\title{
PERSENTASE BOBOT KARKAS AYAM PEDAGING SETELAH PEMBERIAN BERBAGAI DOSIS MINYAK BUAH MERAH (Pandanus Conodeus. lam)
}

\author{
Untung ${ }^{1}$ \\ ${ }^{1)}$ Jurusan Peternakan Fakultas Peternakan Universitas Satya Wiyata Mandala \\ Nabire - Papua \\ Email : untungsuyitno172@gmail.com
}

\begin{abstract}
Abstrak
Penelitian ini bertujuan untuk mengetahui pengaruh pemberian minyak buah merah dalam pakan ayam pedaging terhadap persentase bobot karkas ayam pedaging. Penelitian ini di desain menggunakan rancangan acak lengkap (RAL) dengan empat perlakuan dan setiap perlakuan diulang sebanyak 5 ( lima ) kali sehingga diperoleh 20 satuan percobaan, setiap satuan percobaan terdiri atas 5 ( lima ) ekor ayam. Perlakuan yang diuji yaitu pemberian berbagai dosis minyak buah merah dengan aplikasi tetes mulut. Dosis yang diberikan adalah $0 \mathrm{cc}$ /ekor ( 0 tetes ), 0,05 cc/ekor ( 1 tetes), 0,1 cc lekor ( 2 tetes), dan 0,15 cc/ekor ( 3 tetes). Pemberian minyak buah merah (Pandanus Conodeus Lam) dosis 0,15 cc ( 3 tetes ) meningkatkan pertambahan bobot hidup dan bobot karkas paling baik pada minggu ke $\mathrm{V}$ dan berbeda nyata dengan perlakuan kontrol dan 0,05 cc/ekor. Pemberian minyak buah merah dosis $0,15 \mathrm{cc}$ ( 3 tetes ) menghasilkan bobot hidup 2,046 Kg/ ekor, bobot karkas 1,462 $\mathrm{Kg}$ dan persentase karkas $71 \%$.
\end{abstract}

Kata Kunci : Buah Merah (Pandanus Conodeus. lam), Ayam Pedaging, Bobot Karkas

\begin{abstract}
This study was designed using a complete randomized design (RAL) with four treatments and each treatment was repeated as many as $5 \mathrm{~m}$ (five) times to obtain 20 experimental units, each experimental unit consisting of 5 (five) chickens. The tested treatment was giving various doses of red fruit oil with the application of mouth drops. The given dose is $0 \mathrm{cc} /$ tail ( 0 drops), $0.05 \mathrm{cc} /$ tail ( $1 \mathrm{drop}), 0.1 \mathrm{cc} /$ head ( 2 drops), and $0.15 \mathrm{cc} /$ tail (3 drops). Red (Pandanus Conodeus Lam) dose of $0.15 \mathrm{cc}$ (3 drops) increased live weight gain and best carcass weight at week $\mathrm{V}$ and significantly different from control treatment and $0.05 \mathrm{cc} /$ head. Provision of $0.15 \mathrm{cc}$ red fruit oil (3 drops) resulted in live weight of $2.046 \mathrm{~kg} /$ head, carcass weight of $1,462 \mathrm{~kg}$ and percentage of carcasses $71 \%$.
\end{abstract}

Key Words : Red Fruits (Pandanus Conodeus. lam), Broiler, Weight of carcasses 


\section{PENDAHULUAN}

\section{Latar Belakang}

Buah merah merupakan tanaman endemik Papua, yang akhir-akhir ini populer di kalangan masyarakat karena sangat berkhasiat bagi kesehatan. Minyak dari buah merah dipercaya dapat menyembuhkan dan mencegah berbagai penyakit pada manusia. Penggunaan minyak buah merah pada ternak diharapkan juga dapat menjadi alternatif bagi penyembuhan dan pencegahan berbagai penyakit ternak serta meningkatkan produksi.

Pemanfaatan tanaman buah merah pada ternak khususnya ternak unggas sampai saat ini masih sangat terbatas. Penelitian tentang pemberian minyak buah merah terhadap kualitas produksi pada ayam pedaging belum banyak dilakukan sehingga belum memberikan informasi yang berarti bagi peternak.

Sehubungan hal tersebut, maka perlu dilakukan penelitian pemberian minyak buah merah melalui tetes mulut. Namun permasalahannya adalah pada dosis berapa yang dapat menghasikan prosentase karkas terbaik. Penelitian ini bertujuan untuk mengetahui dosis penambahan minyak buah merah dengan aplikasi tetes mulut yang paling berpengaruh terhadap persentase bobot karkas ayam pedaging. Informasi ilmiah hasil penelitian ini diharapkan dapat berguna sebagai masukan bagi pelaku usaha ayam pedaging di Kabupaten Nabire khususnya dan masyarakat di Papua pada umumnya.

\section{METODE PENELITIAN}

\section{Waktu dan Tempat}

Penelitian ini berlangsung selama 35 hari yakni dimulai pada tanggal 15 Januari 2010 sampai dengan tanggal 19 Februari 2010.

Penelitian dilaksanakan di peternakan ayam pedaging milik Pak Muslimin di Kelurahan Karang Tumaritis Distirk Nabire.

\section{Alat dan Bahan}

Adapun alat dan bahan yang digunakan dalam penelitian ini yakni;

\section{A. Alat}

Alat - alat yang digunakan adalah sebagai berikut: Kandang yang digunakan adalah kandang kelompok sebanyak 20 buah dengan ukuran $\mathrm{P}=$ $100 \mathrm{~cm} \times \mathrm{L}=70 \mathrm{~cm} \times \mathrm{T}=50 \mathrm{~cm}$ ;Wadah tempat pakan ayam kapaistas 500 gram; Tempat air minum ayam kapasitas $3000 \mathrm{ml}$;Spayer 1 unit ;Spoit kapasitas $5 \mathrm{ml}$ Gelas ukur $600 \mathrm{ml}$ ;Timbangan type duduk dengan kapasitas $15 \mathrm{~kg}$;Bohlam 15 watt sebanyak 20 buah.

\section{B. Bahan}

Bahan - bahan yang digunakan dalam penelitian ini adalah sebagai berikut: Bibit ayam umur sehari (DOC) strain SR 707 sebanyak 100 ekor , Minyak buah merah sebanyak $168 \mathrm{cc}$, Ransum ayam pedaging CP 511 dan CP 512, Antiseptik , Kapur pertanian $2 \mathrm{~kg}$, Vita chicks, Vita stress ;Vaksin ND. 


\section{Rancangan Percobaan}

Penelitian ini di desain menggunakan rancangan acak lengkap (RAL) dengan empat perlakuan dan setiap perlakuan diulang sebanyak $5 \mathrm{~m}$ ( lima ) kali sehingga diperoleh 20 satuan percobaan, setiap satuan percobaan terdiri atas 5 ( lima ) ekor ayam. Perlakuan yang diuji yaitu pemberian berbagai dosis minyak buah merah dengan aplikasi tetes mulut. Dosis yang diberikan adalah $0 \mathrm{cc}$ /ekor ( 0 tetes ), 0,05 cc/ekor ( 1 tetes), $0,1 \mathrm{cc} /$ ekor ( 2 tetes), dan 0,15 cc/ekor ( 3 tetes).

Secara matematis model RAL menurut Sastrosupadi ( 2000 ) adalah:

$$
Y \mathbf{i j}=\boldsymbol{\mu}+\mathbf{T i}+\mathbf{i j}
$$

Dimana :

Yij = Respon atau nilai pengamatan dan perlakuan ke- $\mathrm{i}$ dan ulangan ke- $\mathrm{j}$

$\mu \quad=$ Nilai tengah umum

$\mathrm{Ti}=$ Pengaruh perlakuan $\mathrm{ke}-\mathrm{i}$

$\mathrm{ij}=$ Pengaruh galat percobaan dari perlakuan ke -i dan ulangan ke - j

Denah percobaan berdasarkan hasil pengacakan adalah sebagai berikut;

\begin{tabular}{|c|c|c|c|c|}
\hline D5 & B1 & A1 & A5 & C1 \\
\hline B2 & A4 & D4 & B3 & C3 \\
\hline B5 & A3 & C2 & C4 & A2 \\
\hline D2 & D3 & B4 & C5 & D1 \\
\hline
\end{tabular}

Dimana :

A : Perlakuan kontrol (tanpa tetes minyak buah merah)

B : Pemberian minyak buah merah dengan dosis $0,05 \mathrm{cc} /$ ekor atau 1 tetes.

C : Pemberian minyak buah merah dengan dosis 0,1 /ekor atau 2 tetes.

D : Pemberian minyak buah merah dengan dosis $0,1 \mathrm{cc} /$ ekor atau 3 tetes.

\section{Pelaksanaan Percobaan}

\section{Persiapan kandang}

Membuat kandang postal (litter) yang disekat sebanyak 20 kotak; Melakukan pengapuran dan sanitasi kandang dengan penyemprotan larutan antisep ;Menempatkan tempat makanan dan tempat air minum.

\section{Teknik aplikasi minyak buah merah melalui tetes mulut}

Memasukkan minyak buah merah kedalam alat penetesan dengan spoit kemudian diteteskan sesuai dengan dosis. Dosis masing - masing perlakuan adalah; 0,05 cc/ekor ( 1 tetes) untuk perlakuan B, 0,1 cc/ekor ( 2 tetes) untuk perlakuan $\mathrm{C}$ dan 0,15 cc/ekor ( 3 tetes) untuk perlakuan D. Air minum diberikan sesuai dengan kebutuhan per ekor ayam per hari sedangkan untuk percobaan A tidak ditambahkan minyak buah merah sebagai perlakuan kontrol; Memegang ayam dengan hati - hati kemudian dibuka mulutnya dengan jari lalu diteteskan kedalam mulut ayam; Hindari memegang ayam dengan kasar karena akan membuat ayam stress. 


\section{Pemberiaan ransum}

Pemberian ransum dilakukan secara Restriction ( terbatas ), namun disesuaikan dengan standar kebutuhan ayam.

\section{Langkah - langkah pemotongan ayam}

Penangkapan ayam haruslah dengan hati - hati agar tidak stress, ayam ditangkap di bagian kaki;

- Sebelum pemotongan ayam dipuasakan selama 12 jam agar mempermudah keluarnya darah (AAK 1986), tetapi ayam tetap diberikan air minum biasa;

- Penyembelihan dilakukan dengan menggunakan pisau kecil dan tajam, tepat dibagian Vena jugularis dan Arteri carotis;

- Setelah pengeluaran darah benar benar tuntas ( selama 2 menit) maka ayam dicelupkan di air panas $50-60^{\circ} \mathrm{C}$ selama 2 menit untuk mempermudah pencabutan bulu;

- Pemisahan bagian-bagian tubuh ayam, yaitu pengeluaran saluran pencernaan, organ dalam, pemotongan cakar serta kepala sehingga didapatkan karkas. Pengeluaran organ dalam kecuali tembolok dilakukan dengan membelah lapisan kulit ventral dari bagian leher yang menutupi bagian tembolok tersebut. Pemisahan kepala dan cakar dari tubuh dilakukan dengan memisahkan bagian Occipitalis (persendian antara kepala dan leher) yaitu pertautan antara tulang atlas dengan tulang tengkorak, sedangkan pemisahan cakar dilakukan dengan memotong sendi Tibia tarsometatarsus.

\section{Variabel Pengamatan}

Variabel yang diamati dalam penelitian ini adalah :

A.Bobot hidup Ayam Akhir
Pemeliharaan (g/ekor) Jumlah sample ayam hidup yang ditimbang adalah sebanyak 20 sampel dari masing - masing petak. Sampel dipisahkan dan ditimbang berdasarkan perlakuan, sehingga diperoleh berat ayam akhir pemeliharaan. Bobot ayam akhir pemeliharaan dapat dihitung dengan rumus :

$$
\begin{aligned}
& \mathrm{BR}(\mathrm{g})=\frac{T B S}{J S} \\
& \text { Dimana : } \\
& \mathrm{BR} \quad=\text { Berat rata }- \text { rata }(\mathrm{g}) \\
& \mathrm{TBS} \quad=\text { Total berat sampel }(\mathrm{g}) \\
& \mathrm{JS} \quad=\text { Jumlah sampel }(\mathrm{g})
\end{aligned}
$$

\section{B.Berat Karkas (g/ekor)}

Berat karkas ayam diperoleh dari hasil pengurangan berat hidup dikurangi berat kepala, darah, bulu, kaki, dan isi perut. Berat karkas dapat dihitung dengan menggunakan rumus :

$\mathrm{BK}(\mathrm{g} / \mathrm{ekor})=\mathrm{BH}-\mathrm{BO}$

Dimana :

$\mathrm{BK}=$ Berat karkas (g/ekor)

$\mathrm{BH}=$ Berat hidup (g/ekor)

BO = Berat organ kepala, kaki, bulu, darah, dan isi perut (g/ekor)

\section{C.Persentase Karkas}

Persentase karkas ayam diperoleh dengan menghitung perbandingan antara bobot karkas dan berat hidup dikali $100 \%$. Persentase karkas dapat dihitung dengan menggunakan rumus : 


$$
\mathrm{PK}(\%)=\frac{B K}{B H} \quad X 100 \%
$$

Dimana :

PK = Persentase karkas $(\%)$

$\mathrm{BK}=$ Berat karkas (g/ekor)

$\mathrm{BH}=$ Berat hidup (g/ekor)

\section{Analisis Data}

Data yang terkumpul dianalisis dengan teknik analisis keragaman (Analisis of Variance) dan jika terdapat pengaruh yang nyata dari perlakuan akan dilanjutkan dengan uji Duncan multiple range test (DMRT) dengan menggunakan program costat.

\section{HASIL DAN PEMBAHASAN}

\section{Bobot Hidup Ayam Pedaging}

Hasil pengamatan rataan bobot hidup ayam pedaging yang diberikan berbagai dosis minyak buah merah dengan tetes mulut disajikan pada Tabel 1

Tabel 1. Data Bobot Hidup, Bobot Karkas, dan Perhitungan Presentase Bobot Karkas.

\begin{tabular}{|c|c|c|c|}
\hline $\begin{array}{c}\text { Dosis } \\
\text { Minyak } \\
\text { Buah Merah } \\
\text { (cc/ekor) }\end{array}$ & $\begin{array}{c}\text { Bobot } \\
\text { Hidup } \\
\text { (Kg/ekor) }\end{array}$ & $\begin{array}{c}\text { Bobot } \\
\text { Karkas } \\
\text { (Kg/ekor) }\end{array}$ & $\begin{array}{c}\text { Persentase } \\
\text { Bobot } \\
\text { Karkas (\%) }\end{array}$ \\
\hline $\mathrm{A}$ & $1.782 \mathrm{c}$ & $1.207 \mathrm{c}$ & $68 \mathrm{~b}$ \\
\hline $\mathrm{B}$ & $1.860 \mathrm{bc}$ & $1.264 \mathrm{bc}$ & $68 \mathrm{~b}$ \\
\hline $\mathrm{C}$ & $2.013 \mathrm{ab}$ & $1.388 \mathrm{ab}$ & $69 \mathrm{ab}$ \\
\hline $\mathrm{D}$ & $2.046 \mathrm{a}$ & $1.462 \mathrm{a}$ & $71 \mathrm{a}$ \\
\hline
\end{tabular}

Sumber : Hasil Olahan Data Primer, 2009.Keretangan : Angka - angka dalam satu kolom yang diberi salah satu huruf yang sama tidak berbeda nyata berdasarka uji DMRT pada taraf $5 \%$.

Berdasarkan hasil analisis ragam pertambahan bobot hidup pada lampiran 1 menunjukkan bahwa pemberian berbagai dosis minyak buah merah melului tetes mulut berpengaruh ternadap pertambahan bobot hidup pada minggu ke V. Hasil uji DMRT pada Tabel 1 menunjukkan bahwa perbedaan pertambahan bobot badan setelah pemberian berbagai dosis minyak buah merah terjadi antara perlakuan 0 cc/ekor dengan 0,1 cc/ekor dan $0,15 \mathrm{cc}$. Antara perlakuan 0,05 cc/ekor dengan 0,15 cc/ekor juga berbeda nyata. Hal ini disebabkan pengaruh jumlah perbandingan gizi minyak buah merah. Menurut Budi (2004), buah ini mengandung zat - zat alami yang dapat menigkatkan sistim kekebalan tubuh dari proses metabolisme, tak heran jika setelah meminumnya orang akan merasa bugar dan nafsu makannya akan meningkat. Perbedaan kandungan gizi yang relatif cukup bagus akan menghasilkan perbedaan yang nyata. 


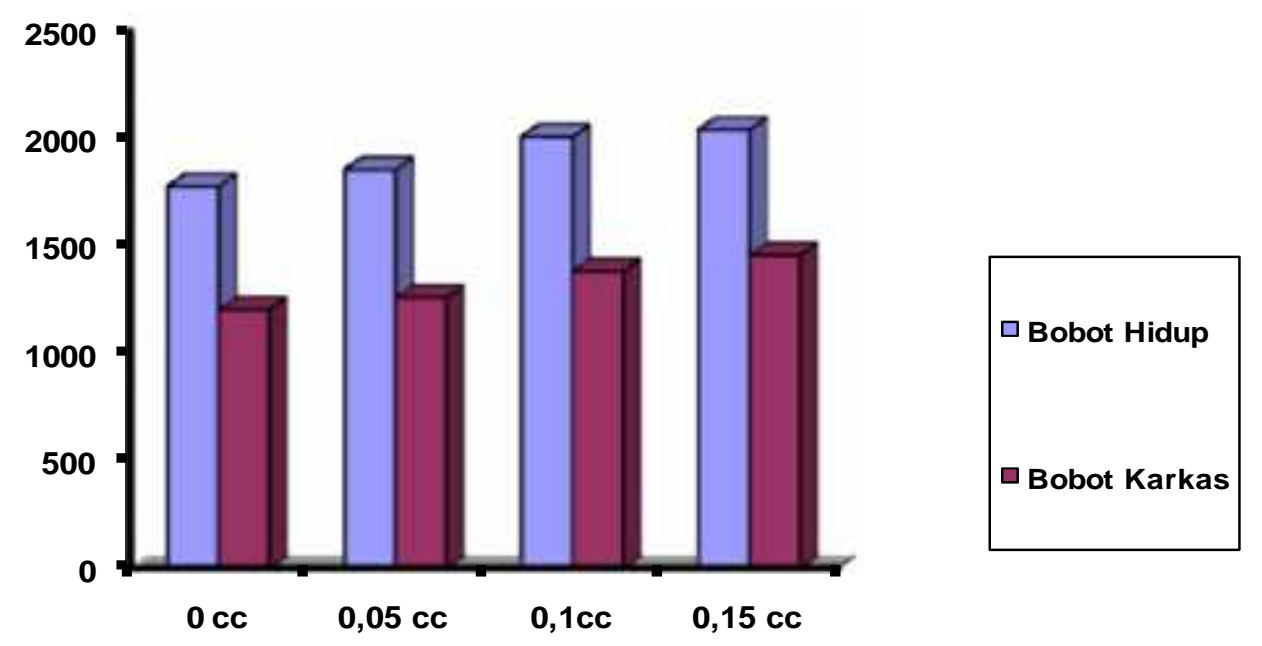

Gambar 1. Histogram Bobot Hidup dan Bobot Karkas pada 5 Minggu Setelah Penambahan Minyak Buah Merah berbagai Dosis melalui Tetes Mulut Berdasarkan Uji DMRT.

\section{Bobot Karkas}

Hasil pengamatan bobot karkas pada minggu ke $\mathrm{V}$ setelah pemberian minyak buah merah melalui tetes mulut disajikan pada Tabel 1 .

Data yang disajikan pada Tabel 1 dan Gambar 1 tersebut menunjukkan bahwa pemberian minyak buah merah berpengaruh nyata terhadap peningkatkan bobot karkas pada setiap perlakuan. Hasil uji DMRT pada Tabel 1 menunjukkan bahwa perbedaan bobot karkas setelah pemberian berbagai dosis minyak buah merah terjadi antara perlakuan 0 cc/ekor dengan 0,1 cc/ekor dan 0,15 cc. Antara perlakuan 0,05 cc/ekor dengan 0,15 cc/ekor juga terjadi penelitian. Hal ini disebabkan karena kandungan gizi pada buah merah dapat melengkapi kebutuhan zat - zat makanan pada ayam pedaging dan juga mengandung betakarotin yang tinggi yang dapat membuat pencernaan pada ayam pedaging lebih efisien sehingga menpengaruhi bobot karkas ayam pedaging yang cukup optimal. Dari hasil penelitian ini, karkas yang dihasilkan secara umum masuk kedalam standar kualitas karkas ayam pedaging dan kualifikasi kualitasnya adalah A. Hal ini disebabkan karena selama penelitian, peneliti sudah menggunakan cara budidaya yang baik.

\section{Persentase Bobot Karkas}

Berdasarkan hasil analisis ragam persentase bobot karkas pada lampiran 3 menunjukkan bahwa pemberian berbagai dosis minyak buah merah melului tetes mulut berpengaruh ternadap persentase bobot karkas pada minggu ke V.. Hasil uji DMRT pada tabel 5 menunjukkan bahwa perbedaan persentase bobot karkas setelah pemberian berbagai dosis minyak buah merah terjadi antara perlakuan 0 cc/ekor dengan 0,05 cc, 0,1 cc/ekor, dan 0,15 cc.. Fenomena ini menunjukkan bahwa pemberian minyak buah merah pada dosis 0,15 cc/ekor menghasilkan persentase bobot karkas ayam pedaging yang lebih tinggi, bila dibandingkan 
dengan perlakuan kontrol ( tanpa minyak buah merah ), 0,05 cc/ekor, 0,1 cc/ekor. Selain itu, persentase bobot karkas yang diberi 0,15 cc/ekor telah masuk pada kriteria persentase karkas yang baik yakni kisaran $65 \%-75 \%$.

\section{KESIMPULAN}

Pemberian minyak buah merah (Pandanus Conodeus Lam) dosis 0,15 cc ( 3 tetes ) meningkatkan pertambahan bobot hidup dan bobot karkas paling baik pada minggu ke $\mathrm{V}$ dan berbeda nyata dengan perlakuan kontrol dan 0,05 cc/ekor. Pemberian minyak buah merah dosis 0,15 cc ( 3 tetes ) menghasilkan bobot hidup 2,046 Kg/ ekor, bobot karkas $1,462 \mathrm{Kg}$ dan persentase karkas $71 \%$.

\section{DAFTAR PUSTAKA}

AAK, 1972. Beternak ayam. Penerbit kanisius.

AAK, 1986. Beternak ayam pedaging. Penerbit yayasan kanisius, Yogyakarta.

Anggorodi R., 1985. Ilmu Makanan Ternak Unggas. Kemajuan Mutakhir. Penerbit Universitas Indonesia ( UI ).

Fadilah R., 2004. Panduan Mengelola Peternakan Ayam Pedaging Komersial. PT. Agromedia Pustaka.

I Made Budi, 2004. Buah merah. Penerbar swadaya.

Murtidjo B. A., 1991. Pedoman Beternak Ayam Pedaging. Yayasan Kanisius, Yogyakarta.
Murtidjo B. A., 1987. Pedoman Beternak Ayam Pedaging. Penerbit Kanisus, Yogyakarta.

Pauwang N., 2006. Performas Produksi Ayam Pedaging (Pedaging) Yang Diberi Minyak Buah Merah (Pandanus Conodeus, Lam) dengan Dosis yang Berbeda. Skripsi Fakultas Pertanian Dan Peternakan Uswim Nabire (Tidak Diterbitkan).

Rasyaf M., 1992. Pengelolaan Peternakan Unggas Ayam Pedaging. Yayasan Kanisius, Yogyakarta.

Rasyaf M., 1993. Beternak Ayam Pedaging. Yayasan Kanisus, Yogyakarta.

Sastrosupadi, A. Rancangan Percobaan Praktis Bidang Pertanian. Kanisius, Yogyakarta.

Siregar, A.P.,M. Sabarani dan S. Pramu, 1982. Teknik Beternak Ayam Pedaging di Indonesia. Mergie Group, Jakarta.

Soeharsono, 1997. Respon Pedaging Terhadap Berbagai Kondisi Lingkungan. Universitas Pajajaran, Bandung.

Tilman, A. H. Hartadi, S. Reksohadiprojo, S. Prawirokusumo, dan S. Lebdosoekojo, 1991. Ilmu Nutrisi Unggas. Gadjah Mada University Press. Yogyakarta.

Tobing V., 2002. Beternak Ayam Pedaging Bebas Antibiotik. Penebar Swadaya. Jakarta.

Wahyu J., 1988. Ilmu Nutrisi Unggas. Gadjah Mada University Press. Yogyakarta. 